\title{
Multi-professional meetings on health checks and communication in providing nutritional guidance for infants and toddlers in Japan: a cross-sectional, national survey-based study
}

Midori Ishikawa ${ }^{1 *}$ (D) Kumi Eto ${ }^{2}$, Mayu Haraikawa ${ }^{3}$, Kemal Sasaki $^{5}$, Zentaro Yamagata ${ }^{6}$, Tetsuji Yokoyama ${ }^{1}$, Noriko Kato ${ }^{1,7}$, Yumiko Morinaga ${ }^{8}$ and Yoshihisa Yamazaki ${ }^{4}$

\begin{abstract}
Background: Health personnel must provide continuous support in response to problematic results from health checks of infants and toddlers (hereinafter "infant[s]"). Among this support, it is important for health personnel to provide nutritional guidance to families as a collaborative effort between the staff from multiple disciplines and community organizations. This study aimed to clarify the factors affecting collaboration with community organizations in providing nutritional guidance to families following health checks for infants in Japan.

Methods: The design of this study consisted of a cross-sectional, multilevel survey. A self-administered questionnaire was mailed to all municipalities (1741 towns and cities) in Japan to be completed by the person responsible for nutrition advice. The research was performed in August 2015. We obtained 988 valid responses (response rate of 56.7\%).

To identify the factors that affect the collaboration with community organizations in providing nutritional guidance, we determined how municipalities responded to infants needing support (five items), how municipalities evaluated health guidance (five items), the number of distributed maternal and child health handbooks, and the number of infants who received follow-up evaluations.

Results: The results of multivariate analyses showed that the factors related to successful community collaboration in providing nutritional guidance included holding a multi-professional staff meeting after health checks (post-conference; odds ratio [OR], 2.34; $P=0.001$ ); following up children suspected of having developmental and mental disabilities or delays before entering elementary school $(\mathrm{OR}, 1.77 ; P=0.0004)$; and considering dental caries data from dental checkups in providing health guidance $(\mathrm{OR}, 1.56 ; P=0.003)$.
\end{abstract}

Conclusions: Holding a multi-professional meeting after infant health checks (post-conference) was strongly associated with community collaboration in providing nutritional guidance for infants.

Keywords: Infant health checks, Nutritional guidance, Community collaboration, Multi-professional meeting, Japan

\footnotetext{
*Correspondence: ishikawa.m.aa@niph.go.jp

'Department of Health Promotion, National Institute of Public Health, 2-3-6

Minami, Wako, Saitama 351-0197, Japan

Full list of author information is available at the end of the article
}

(c) The Author(s). 2018 Open Access This article is distributed under the terms of the Creative Commons Attribution 4.0 International License (http://creativecommons.org/licenses/by/4.0/), which permits unrestricted use, distribution, and reproduction in any medium, provided you give appropriate credit to the original author(s) and the source, provide a link to the Creative Commons license, and indicate if changes were made. The Creative Commons Public Domain Dedication waiver (http://creativecommons.org/publicdomain/zero/1.0/) applies to the data made available in this article, unless otherwise stated. 


\section{Background}

In Japan's maternal and child health $(\mathrm{MCH})$ policy, Healthy Parents and Children 21 (Second Phase), the collaboration between the municipality and stakeholders in the community (e.g., kindergartens, preschools, child welfare facilities) is required to provide ongoing support for children and parents in need of health and nutritional care guidance [1]. By using a multi-professional approach-in which experts collaborate to meet the needs of the infant and parent-the appropriate quality of healthcare support can be provided [2, 3]. For example, there are cases of parents being unwilling to acknowledge concerns about the delayed development of their child based on the results of health checks. Parents may refuse to accept the guidance provided by public health nurses about their child's development. Other issues involve children having an unbalanced diet. In such cases, dietitians are expected to provide nutritional guidance while considering the needs of the children and parents $[2,4]$. Community collaboration may be required to properly respond to infants and parents needing support, health evaluation, and nutritional guidance. It is therefore important to provide nutritional guidance based on the results of infant health checks and as a collaborative effort between multi-professional staff and community organizations.

One study evaluating infant health status in the United States showed that positive weight change is related to an effective network of community collaborations [5]. Access to quality childcare services using community resources on the results of infant health status assessments is also important in improving parental behavior and reducing the need for emergency medical care for infants $[6,7]$. However, no studies in Japan have investigated this topic.

In Japan, infant health checks are required by the Maternal and Child Health Law [8]. The main purpose of infant health checks and health guidance is to clarify explicit and potential health concerns and to support parents and children in dealing with these concerns $[8,9]$. In 2015 , the participation rate for health checks was $95.6 \%$ for infants aged 3-4 months, $95.7 \%$ for those aged 1.6 years, and $94.3 \%$ for those aged 3 years [10].

Before or after health checks in Japan, a multi-professional meeting is convened by health staff to identify health concerns (a "pre-/post-conference"). Although this form of conference is not a mandate of the designated country, this form has been adopted for information sharing among staff to connect health checks and health guidance for children in municipalities. At the pre-conference, the staff discuss pre-established concerns about each child. At the post-conference, the children who require follow-up evaluations are confirmed. In some cases, continuous support (follow-up) [11, 12], as well as the provision of nutritional guidance in conjunction with community collaborations, may be required. In such cases, it is important to share information about infant health checks with community organizations. This sharing allows deciding the best approaches to support children and parents, evaluate responses to their needs, and assess the outcomes of those activities [5]. However, few studies have investigated factors that affect the ability of health personnel and community organizations to collaborate on providing nutritional guidance to families [13]; moreover, no studies have addressed this topic in Japan.

This survey aimed to clarify the proportion of municipalities in Japan cooperating with communities in providing nutritional guidance to families whose infants received health checks, and to identify the factors related to collaboration with community organizations in providing nutritional guidance.

\section{Methods \\ Study municipalities and procedure}

This study was a cross-sectional survey of all 1741 municipalities in Japan. We used a self-administered questionnaire to determine whether infant health checks were being carried out and whether health and nutritional guidance was being provided. A copy of the questionnaire was mailed to each municipality. The department responsible for nutritional guidance following infant health checks was asked to complete the questionnaire. The director of the department then returned the questionnaire by mail or fax.

This research was performed in August 2015. In total, 1172 municipalities completed the questionnaire (response rate of 67.3\%). Only questionnaires with complete responses to the items included in our analysis were considered valid, providing 988 valid questionnaires for analysis (response rate of 56.7\%).

\section{Measurement}

The questionnaire items included indicators of existing policy measures and guidelines $[1,2,14,15]$ of the Ministry of Health, Labour and Welfare; these guidelines were used in a national nutrition survey of preschool children [16]. The reliability of the items was previously confirmed [17-19].

The dependent variable was whether community collaboration is involved in providing guidance on infant nutrition. The survey respondents were asked: "Does your municipality provide nutritional guidance or education targeting infants and parents in collaboration with any organizations or groups, such as nursery schools, kindergartens, welfare facilities, or related agencies in the community, and do you evaluate those activities?" [18]. Health personnel were 
asked to choose an answer from the following categories: 1) We collaborate with community organizations and evaluate the activities; 2) We collaborate with community organizations but do not evaluate the activities; and 3) We do not collaborate with any organization. We designated municipalities that answered either 1 or 2 as the collaborating group and those that answered three as the non-collaborating group.

We expected certain factors to be associated with such collaboration, including methods for carrying out infant health checks, methods for determining how to respond to infants and parents needing support (five items), and methods for evaluating health guidance (five items). We also asked about potential confounding factors related to infant health checks. They included the annual number of distributed Mother and Child Health $(\mathrm{MCH})$ handbooks, the annual number of infants who received a follow-up and municipality category by number of children eligible for health checks at 3 years old.

These items were chosen because they are important indicators of the health and nutrition of infants in Japan, and there are clear differences between municipalities. A copy of the $\mathrm{MCH}$ Handbook is provided for all pregnant women and provides a consistent health and information-provision record during pregnancy, delivery, and early years of child rearing. At every infant health check, information related to health and nutritional status are entered in the handbook, to determine suitable follow-up.

A previous study using the same data reported the validity of the municipality categories for the geographical area, the population size, and the number of children eligible for health checks at 3 years old [19]. However, the report did not show the relationship between the municipality category and community collaboration on nutritional guidance for infants. We therefore included whether category was related to the collaboration items, as a possible confounding factor.

The Appendix shows the five items addressing "how staff responded to infants and parents needing support" and "the evaluation of health guidance." The possible answers were yes or no.

\section{Statistical analysis}

To determine the response to infants and parents needing support (five items) and methods used to evaluate health guidance (five items), we performed an analysis comparing the answers of the collaborating and non-collaborating municipalities to the survey items about the methods used. We analyzed the results using the Cochran-Mantel-Haenszel test. Using correspondence analysis, we analyzed the relationships between the 11 items (one item on collaborating with community organizations; five items on determining responses to infants and parents; and five items on evaluating health guidance).

We performed univariate analysis for each factor using a logistic regression model based on the results of the correspondence analysis. The analyzed factors were those that were expected to be associated with collaboration in nutritional guidance: implementing a pre-conference; sharing medical records; sharing verbal information with responsible staff; implementing a post-conference; providing feedback to public health nurses and related organizations; evaluating health guidance for parents; using dental caries data in health guidance; evaluating health guidance and follow-up; and providing follow-up evaluations for infants before or after beginning elementary school.

To identify factors important for community collaboration, we performed stepwise logistic regression using the following variables: holding pre-conferences; sharing medical records; sharing verbal information with staff; holding post-conferences; providing feedback to public health nurses and related organizations; evaluating health guidance for parents; using dental caries information in health guidance; evaluating health guidance and follow-up; and providing follow-up evaluations for children who have entered or not entered elementary school. These data were adjusted for the annual number of distributed $\mathrm{MCH}$ handbooks, the annual number of infants who received follow-up evaluations, and the annual number of 3-year-olds who underwent health checks (model 1).

Statistical analysis was conducted using SAS software, version 9.2 (SAS Institute, Inc., Cary, NC, USA). A $P$ value of $<0.05$ was considered statistically significant.

\section{Results}

Table 1 shows the comparison between community collaboration to provide nutritional guidance with distribution of $\mathrm{MCH}$ Handbook, number of infants who received follow-up, and municipality category by number of children eligible for health checks at 3 years old. The proportion of municipalities that collaborated with community organizations in providing nutritional guidance based on infant health checks (collaborating group) was $69.5 \%$. The proportion that did not collaborate with any community organizations (non-collaborating group) was $30.5 \%$. There were no significant differences between the two groups for the annual number of $\mathrm{MCH}$ handbooks distributed, the annual number of infants who received follow-up and 
Table 1 Comparison between community collaboration in providing nutritional guidance with distribution of MCH Handbook, number of infants who received follow-up, and municipality category by number of children eligible for health checks at 3 years old

\begin{tabular}{|c|c|c|c|c|c|c|}
\hline & & \multicolumn{2}{|c|}{ Collaborating group } & \multicolumn{2}{|c|}{ Non-collaborating group } & \multirow[t]{2}{*}{$n=988$} \\
\hline & & no & $\%$ & no & $\%$ & \\
\hline & & 687 & 69.5 & 301 & 30.5 & $p$ \\
\hline & & mean & SD & mean & SD & \\
\hline \multicolumn{2}{|c|}{ Number of distributions of MCH Handbook/year } & 693.7 & 1703.9 & 698.4 & 1197.5 & 0.240 \\
\hline \multicolumn{2}{|c|}{ Number of infants who received follow-up/year } & 58.3 & 140.7 & 70.0 & 164.5 & 0.899 \\
\hline \multicolumn{2}{|c|}{$\begin{array}{l}\text { Municipality category by scale of number of subjects to health } \\
\text { checks for 3-year-old children }\end{array}$} & no & $\%$ & no & $\%$ & \\
\hline $1<8$ & । & 11 & 1.6 & 10 & 3.3 & 0.239 \\
\hline $8 \leq \|<54$ & $\|$ & 119 & 17.3 & 43 & 14.3 & \\
\hline $54 \leq 11 \mid<391$ & III & 301 & 43.8 & 123 & 40.9 & \\
\hline $39 \leq \mathbb{I V}<2916$ & IV & 218 & 31.7 & 106 & 35.2 & \\
\hline $2916 \leq V$ & V & 38 & 5.5 & 19 & 6.3 & \\
\hline
\end{tabular}

$\mathrm{p}$ for homogeneity between 2 groups by Cochran-Mantel-Haenszel

the municipality category by number of children eligible for health checks at 3 years old.

Table 2 shows the relationship between community collaboration to provide nutritional guidance for infants and parents, decisions on how staff responded to infants and parents needing support (five items), and methods used to evaluate health guidance (five items).

Collaborating municipalities were more likely to implement a pre-conference $(P=0.014)$ and a post-conference $(P<0.001)$ and to provide feedback to public health nurses $(P=0.023)$. The collaborating group also consisted of more municipalities that evaluated health guidance for parents $(P=0.002)$, used dental caries information in health guidance $(P=0.001)$, followed up children prior to elementary school $(P=0.001)$, and evaluated the relevance of health guidance and follow-ups $(P=0.005)$.

Figure 1 maps the results of the correspondence analysis for the relationships between community collaboration in providing nutritional guidance, decisions on the response to infants and parents needing support, and evaluation of health guidance. Items on the evaluation of health guidance were closer to community collaboration in provision of nutritional guidance than items on determining the response to infants and parents. A post-conference was closely associated with community collaboration in providing nutritional guidance in items addressing decisions on the response to infants and parents needing support. The positions of the pre-conference and post-conference were far apart, which indicates that these conferences might have different roles.

\section{Using logistic analysis}

Table 3 shows the factors in the health check activities that were related to successful community collaboration in nutritional guidance. Following normalization (Model 1), these factors included the following: having a pre-conference (odds ratio $[\mathrm{OR}]=1.45 ; 95 \%$ confidence interval $[\mathrm{CI}]: 1.08-1.94 ; P=0.014)$, having a post-conference $(\mathrm{OR}=2.82 ; 95 \% \mathrm{CI}: 1.72-4.61 ; P<0.001)$, providing feedback to public health nurses and related stakeholders $(\mathrm{OR}=1.54 ; 95 \%$ CI: $1.11-2.15 ; P=0.010)$, evaluating health guidance for parents needing support $(\mathrm{OR}=1.70$; 95\% CI: $1.22-2.37 ; P=0.002)$, using data about dental caries in health guidance $(\mathrm{OR}=1.82 ; 95 \% \mathrm{CI}$ : $1.37-2.42 ; P<$ 0.001 ), following up children before they began elementary school $(\mathrm{OR}=2.01 ; 95 \% \mathrm{CI}: 1.48-2.73 ; P<0.001)$, and evaluating the relevance of health guidance $(\mathrm{OR}=1.58$; 95\% CI: $1.14-2.18 ; P=0.005$ ).

In the multivariate analysis, the factors related to successful community collaboration in nutritional guidance included the following: having post-conferences $(\mathrm{OR}=2.34 ; 95 \% \mathrm{CI}: 1.39-3.94 ; P=0.001)$, following up children before they entered elementary school (OR = 1.77; 95\% CI: $1.29-2.43 ; P=0.0004)$, and using data on dental caries in health guidance $(\mathrm{OR}=1.56 ; 95 \% \mathrm{CI}$ : $1.16-2.10 ; P=0.003)$.

\section{Discussion}

Factors related to community collaboration in nutritional guidance

In this study, community collaboration in providing nutritional guidance was strongly related to the implementation of a multi-professional meetings after health checks (post-conferences). This finding is consistent with previous 
Table 2 Relationship between community collaboration in nutritional guidance for infants and parents, decisions on how staff responded to infants and parents needing support, and methods used to evaluate health guidance

\begin{tabular}{|c|c|c|c|c|c|c|}
\hline & & Colla & ng group & Non- & ating group & $n=988$ \\
\hline & & no & $\%$ & no & $\%$ & \\
\hline & & 687 & 69.5 & 301 & 30.5 & $\mathrm{p}$ \\
\hline How staff responded to infants and parents needing support (5 items) & & & & & & \\
\hline Implement a pre-conference & Yes & 510 & 74.2 & 200 & 66.5 & 0.014 \\
\hline & No & 177 & 25.8 & 101 & 33.6 & \\
\hline Share medical records & Yes & 458 & 66.7 & 203 & 67.4 & 0.812 \\
\hline & No & 229 & 33.3 & 98 & 32.6 & \\
\hline Share verbal information with responsible staff & Yes & 426 & 62.0 & 181 & 60.1 & 0.577 \\
\hline & No & 261 & 38.0 & 120 & 39.9 & \\
\hline Implement a post-conference & Yes & 654 & 95.2 & 264 & 87.7 & $<.0001$ \\
\hline & No & 33 & 4.8 & 37 & 12.3 & \\
\hline Provide feedback to public health nurses and related organizations & Yes & 547 & 79.6 & 220 & 73.1 & 0.023 \\
\hline & No & 140 & 20.4 & 81 & 26.9 & \\
\hline Methods used to evaluate health guidance (5 items) & & & & & & \\
\hline Evaluate health guidance for parents & Yes & 195 & 28.4 & 57 & 18.9 & 0.002 \\
\hline & No & 492 & 71.6 & 244 & 81.1 & \\
\hline Use dental caries data in health guidance & Yes & 316 & 46.0 & 97 & 32.2 & $<.0001$ \\
\hline & No & 371 & 54.0 & 204 & 67.8 & \\
\hline Provide follow-up evaluations for infants before beginning elementary school & Yes & 272 & 69.6 & 74 & 24.6 & $<.0001$ \\
\hline & No & 415 & 60.4 & 227 & 75.4 & \\
\hline Provide follow-up evaluations for infants after beginning elementary school & Yes & 11 & 1.6 & 4 & 1.3 & 0.747 \\
\hline & No & 676 & 98.4 & 297 & 98.7 & \\
\hline Evaluate health guidance and follow-up & Yes & 206 & 30.0 & 64 & 21.3 & 0.005 \\
\hline & No & 481 & 70.0 & 237 & 78.7 & \\
\hline
\end{tabular}

$\mathrm{p}$ for homogeneity between 2 groups by Cochran-Mantel-Haenszel

reports in which sharing information among staff enabled professionals to both create a shared vision, strong leadership, and broad collective goals and to clarify strengths and priorities for developing and launching projects [20]. The importance of selecting the most appropriate approach to create a collaboration has been reinforced by health data and reliable information showing the results of environmental and behavioral change [21]. If staff are unable to share child health information, then it will be unclear whether a particular response or approach is appropriate [22]. It is necessary to confirm why some municipalities do not conduct post-conferences. Post-conferences may help to establish a better system for health checks and nutritional improvement for infants.

\section{Multidisciplinary collaboration for nutritional support in the community}

In Japan, health checks are used to make an accurate assessment of the needs of infants and their parents.
Parents may continue to experience difficulties and require support throughout their child's early years $[2,16]$. It is therefore important to establish a system that enables continuous support of infants and parents in the community $[2,21,23]$.

According to Japan's national infant nutritional survey, an unbalanced diet (including snacks and soft drinks) leads to dietary issues in children. The proportion of children with such diets is significantly higher in low-income households [16]. Other studies have reported a relationship between the consumption of sugary drinks and poor eating behavior among infants and children [24-26].

One of the main objectives of community collaboration is to monitor the progress of infants and parents who require particular support in certain areas, including nutrition [21]. A multi-sectorial approach is required to address various dimensions of maternal and child healthcare, including environmental health [27]. 


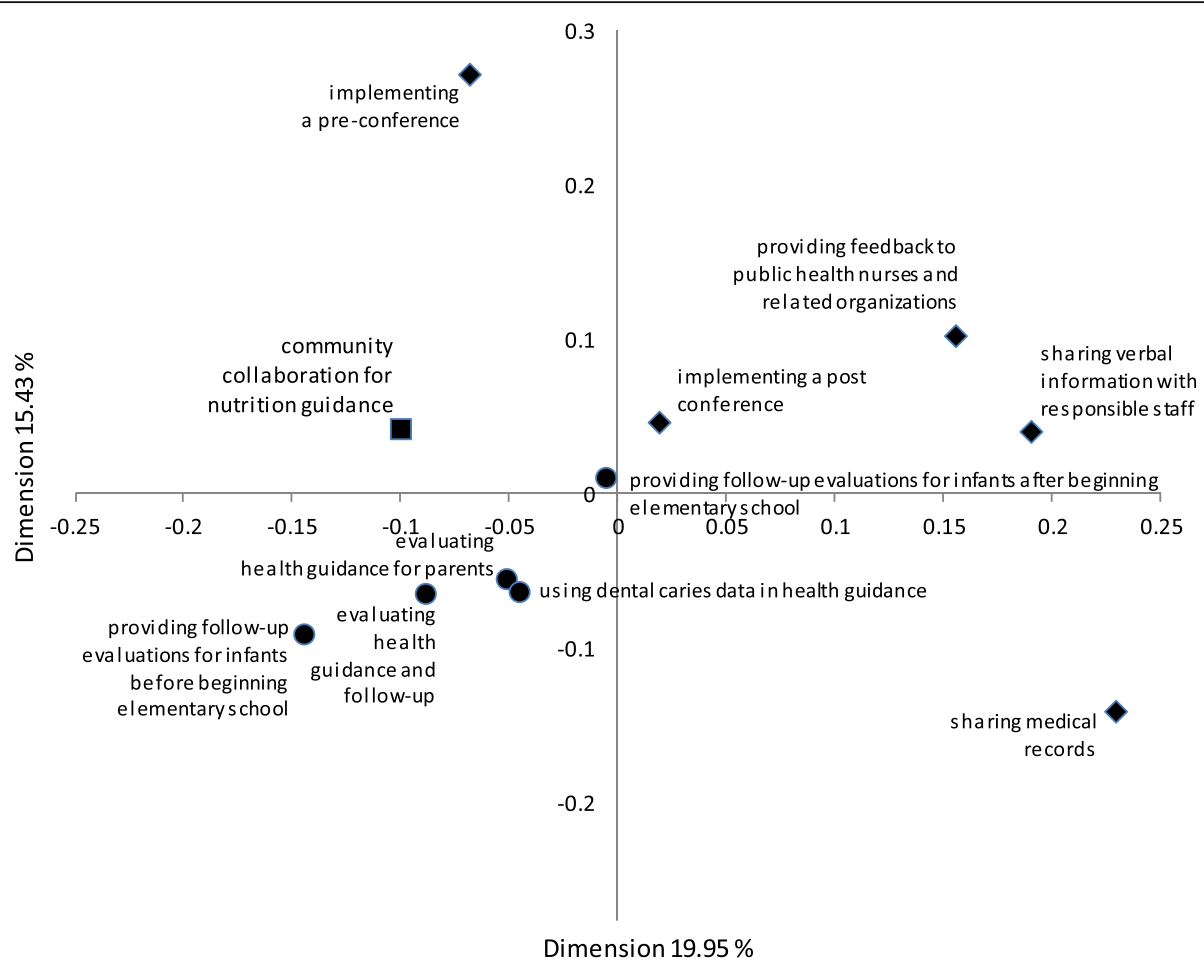

Fig. 1 Relationships between "community collaboration for nutritional guidance", and items on "how staff responded to infants and parents needing support" and "methods used to evaluate health guidance", from the correspondence analysis. Key: • How staff responded to infants and parents needing support (5 items); • Methods used to evaluate health guidance (5 items)

Health professionals such as dietitians can then be involved in deciding whether further assistance is necessary or whether the issues have been resolved with the support provided [2,5]. It is important that staff from multiple health disciplines and community groups are involved in discussions about infants and parents at post-conferences, as this involvement enables a consensus on the need for monitoring, continued support, or follow-up evaluations with home visits [6, 23].

This study found that the factors strongly related to community collaboration in providing nutritional guidance included sharing information about infant dental checkups and the results of follow-up activities before children entered elementary school. Sharing this information will lead to ongoing support throughout the child's education [10]. The life course perspective is a critical addition to this work: it highlights the importance of ensuring that infants and children live in supportive community environments that will foster optimal health, development, and well-being throughout their lives [3, 7].

It is important to develop long-term support systems for infants and parents by sharing information, especially about food and nutrition, between community organizations such as nursery schools, pediatric clinics, kindergartens, child welfare facilities, associations for the promotion of better dietary habits, community cafeterias for children, and other governmental and non-governmental organizations [10].

This study had some limitations. First, its cross-sectional design suggests that no causal relationships can be inferred, such that reverse causation or simple correlation could account for the observations. Second, the final response rate of $56.7 \%$ was relatively low. The questionnaire was not administered to individuals, and it covered a broad range of disciplines; moreover, staff operating in different fields may have responded differently to certain items. Local government staff may also have the lacked time to complete the questionnaire during working hours and, in particular, to obtain a consensus from other staff members. Characteristics of municipalities that did not respond (around one third in total) were almost the same as those that did, including population size (small, medium and large population). One of the reasons why some municipalities did not respond may have been because that they have no full-time staff in charge of nutrition. During the study period, several municipalities responded to explain that they only 
Table 3 Factors in health check activities that are related to successful community collaboration in nutritional guidance, assessed by logistic analysis

\begin{tabular}{|c|c|c|c|c|c|c|c|c|c|}
\hline \multirow{2}{*}{ item } & & \multicolumn{4}{|c|}{ Model $1^{\mathrm{a}}$} & \multicolumn{3}{|c|}{ Stepwise } & \multirow{2}{*}{$\begin{array}{l}n=988 \\
\mathrm{p}\end{array}$} \\
\hline & & \multirow[t]{2}{*}{ OR } & \multicolumn{2}{|c|}{$95 \% \mathrm{Cl}$} & \multirow[t]{2}{*}{$\mathrm{p}$} & \multirow[t]{2}{*}{ OR } & \multicolumn{2}{|c|}{$95 \% \mathrm{Cl}$} & \\
\hline \multicolumn{7}{|l|}{ How staff responded to infants and parents needing support (5 items) } & & & \\
\hline \multirow[t]{2}{*}{ Implement a pre-conference } & Yes & 1.45 & 1.08 & 1.94 & 0.014 & 1.22 & 0.89 & 1.66 & 0.212 \\
\hline & No & 1.00 & & & & 1.00 & & & \\
\hline \multirow[t]{2}{*}{ Share medical records } & Yes & 1.01 & 0.74 & 1.38 & 0.949 & & & & \\
\hline & No & 1.00 & & & & & & & \\
\hline \multirow[t]{2}{*}{ Share verbal information with responsible staff } & Yes & 1.13 & 0.85 & 1.52 & 0.405 & & & & \\
\hline & No & 1.00 & & & & & & & \\
\hline \multirow[t]{2}{*}{ Implement a post-conference } & Yes & 2.82 & 1.72 & 4.61 & $<.0001$ & 2.34 & 1.39 & 3.94 & 0.001 \\
\hline & No & 1.00 & & & & 1.00 & & & \\
\hline \multirow[t]{2}{*}{ Provide feedback to public health nurses and related organizations } & Yes & 1.54 & 1.11 & 2.15 & 0.010 & & & & \\
\hline & No & 1.00 & & & & & & & \\
\hline \multicolumn{10}{|l|}{ Methods used to evaluate health guidance (5 items) } \\
\hline \multirow[t]{2}{*}{ Evaluate health guidance for parents } & Yes & 1.70 & 1.22 & 2.37 & 0.002 & & & & \\
\hline & No & 1.00 & & & & & & & \\
\hline \multirow[t]{2}{*}{ Use dental caries data in health guidance } & Yes & 1.82 & 1.37 & 2.42 & $<.0001$ & 1.56 & 1.16 & 2.10 & 0.003 \\
\hline & No & 1.00 & & & & 1.00 & & & \\
\hline \multirow[t]{2}{*}{ Provide follow-up evaluations for infants before beginning elementary school } & Yes & 2.01 & 1.48 & 2.73 & $<.0001$ & 1.77 & 1.29 & 2.43 & 0.000 \\
\hline & No & 1.00 & & & & 1.00 & & & \\
\hline \multirow[t]{2}{*}{ Provide follow-up evaluations for infants after beginning elementary school } & Yes & 1.19 & 0.37 & 3.76 & 0.772 & & & & \\
\hline & No & 1.00 & & & & & & & \\
\hline \multirow[t]{2}{*}{ Evaluate health guidance and follow-up } & Yes & 1.58 & 1.14 & 2.18 & 0.005 & & & & \\
\hline & No & 1.00 & & & & & & & \\
\hline
\end{tabular}

${ }^{a}$ Model 1: Adjusted for category of subject in 3-year-old infant health examinations, number of Mother Child Handbooks distributed per year, and number of infants followed up per year

OR Odds ratio, Cl Confidence interval

had part-time staff responsible for nutritional guidance, so could not cooperate. In future surveys, it will be necessary to consider the investigation method to ensure that municipalities are not excluded because of the employment situation of staff in charge of providing nutritional guidance. Responses to the survey may also have been limited to municipalities that actively conduct health checks. A follow-up study using face-to-face interviews with health workers should be considered. Fourth, our analysis was restricted to items that could apply to all municipalities. Future investigations should examine whether the response options are unique to Japan. Municipal income was not included as a confounding factor in this survey, but should be included in a future study.

Despite these limitations, this study found relationships between community collaboration in providing nutritional guidance and the implementation of post-conferences, the follow-up evaluation of children suspected of having developmental and mental difficulties before they enter elementary school, and the use of dental checkup results in health guidance for parents and their children. The results of this study are significant because very few studies to date have examined the links between nutritional guidance and infant health checks.

\section{Conclusions}

This study found that sharing information in a multi-professional meeting following infant health checks (a post-conference) was strongly associated with successful community collaboration in providing nutritional guidance. It highlights the importance of ensuring that infants and children live in supportive community environments that will foster optimal health, development, and well-being throughout their lives. 


\section{Appendix}

Table $\mathbf{4}$ Items of questionaiire on factors to be associated with community collaboration in nutritional guidance for infants and parents

How staff responded to infants and parents needing support (5 items)

Do you share information with staff from different disciplines at meetings before health checks (pre-conference)?

Do you share medical record information?

Do you verbally share information with responsible public health staff?

Do you share information with staff from different disciplines at meetings after health checks (post-conference)?

Do you provide feedback on infant health information to the public health nurse responsible for the area of residence and related stakeholders?

Methods used to evaluate health guidance (5 items)

Do you evaluate the relevance of health guidance for parents who are having difficulties raising their child?

Do you use data about dental caries from dental health checks in health guidance?

Do you follow up children who are suspected of having developmental or mental disabilities or delays before entering elementary school?

Do you follow up children suspected of having developmental or mental disabilities or delays after entering elementary school?

Do you evaluate the relevance of health guidance and follow-ups, including for children who are not unhealthy but where there is some cause for concern?

\section{Abbreviations}

Cl: Confidence interval; MCH: maternal and child health; MHLW: Ministry of Health, Labour and Welfare; OR: Odds ratio; SD: Standard deviation

\section{Acknowledgements}

This study was supported by the Japan Agency for Medical Research and Development Grants and Health and Labour Sciences Research Grants, Japan. We also thank the municipalities who participated in this study.

\section{Funding}

This study was supported by the Japan Agency for Medical Research and Development Grants (H27-28 16gk0110010j1002) and Health and Labour Sciences Research Grants (H29Sukoyaka-Ippan 003). This research did not receive any specific grant from funding agencies in the commercial, or not-for-profit sectors.

\section{Availability of data and materials}

The dataset analyzed during the current study available from the corresponding author on reasonable request and with permission of YY.

\section{Authors' contributions}

Ml designed the study, collected and analyzed the data and drafted the manuscript; $K E, M H, K S, Z Y, K N$, YM and $Y Y$ conceived and designed the study, collected the data and helped draft the manuscript; and TY helped analyze the data and draft the manuscript. All authors have read and approved the final version of the manuscript and agree with the order of presentation of the authors.

\section{Ethics approval and consent to participate}

This study was approved by the Ethics Committee of the Faculty of Medicine at the Aichi Children's Health and Medical Center, Obu, Aichi, Japan (\#201518, July 31, 2015). We sent the request document to the survey to all municipalities. Responses to questionnaires from municipalities were regarded as a consent.

\section{Consent for publication}

Not applicable.

\section{Competing interests}

The authors declare that they have no competing interests.

\section{Publisher's Note}

Springer Nature remains neutral with regard to jurisdictional claims in published maps and institutional affiliations.

\section{Author details}

'Department of Health Promotion, National Institute of Public Health, 2-3-6 Minami, Wako, Saitama 351-0197, Japan. ${ }^{2}$ Faculty of Nutrition, Kagawa Nutrition University, 3-9-21 Chiyoda, Sakado, Saitama 350-0288, Japan. ${ }^{3}$ Department of Child Studies, Faculty of Child Studies, Seitoku University, 550 Iwase, Matsudo, Chiba 271-8555, Japan. ${ }^{4}$ Child Health Center, Aichi Children's Health and Medical Center, 426-7, Morioka, Obu, Aichi 474-8710, Japan. ${ }^{5}$ Department of Food and Health Sciences, Jissen Women's University, 4-1-1 Osakaue, Hino, Tokyo 191-8510, Japan. ${ }^{6}$ Faculty of Medicine, University of Yamanashi, 1110 Shimokato, Chuo, Yamanashi 409-3898, Japan. ${ }^{7}$ Present Address: Department of Early Childhood Care and Education, Jumonji University, 2-1-28 Sugasawa, Niizashi, Saitama 352-8510, Japan. ${ }^{8}$ Faculty of Medicine, School of Nursing Public Health Nursing, Kagawa University, 1750-1, Ikenobe, Miki, Kita, Kagawa 761-0793, Japan.

Received: 20 September 2017 Accepted: 27 September 2018 Published online: 15 October 2018

\section{References}

1. Ministry of Health, Labour and Welfare (MHLW): Healthy Parents and. Children 21(second), 2015(in Japanese) http://www.mhlw.go.jp/file/06 Seisakujouhou-11900000-Koyoukintoujidoukateikyoku/0000067539. pdf\#search=\%27\%E5\%81\%A5\%E3\%82\%84\%E3\%81\%8B\%E8\%A6\%AA\% E5\%AD\%9021\%E7\%AC\%AC\%E4\%BA\%8C\%E6\%AC\%A1\%27. Accessed 5 Sep 2017.

2. Study group on health checkup and health guidance for maternal and child health through multi-occupational cooperation (SGHC): Standard health checkup and health guidance in infant and early childhood. 2015 (in Japanese) http://www.mhlw.go.jp/file/06-Seisakujouhou-11900000Koyoukintoujidoukateikyoku/tebiki.pdf. Accessed 5 Sep 2017.

3. Shrimali P, Luginbuhl J, Malin C, Flournoy R, Siegel A. The building blocks collaborative: advancing a life course approach to health equity through multi-sector collaboration. Maternal Child Health J. 2014;18:373-9.

4. Mustila T, Keskinen P, Luoto R. Behavioral counseling prevent childhood obesity-study protocol of a pragmatic trial in maternity and child health care. BMC Pediatr. 2012;12(93) https://doi.org/10.1186/1471-2431-12-93.

5. Darnell AJ, Barile JP, Weaver SR, Harper CR, Kupermine GP, Emshoff JG. Testing effects of community collaboration on rates of low infant birthweight at county level. Am J Community Psychol. 2013;51:398-406. https://doi.org/10.1007/s10464-012-9559-x.

6. Dodge KA, Goodman WB, Murphy RA, O'Donnell K, Sato J, Guptill S. Implementation and randomized controlled trial evaluation of universal postnatal nurse home visiting. Am J Public Health. 2014;104:S143 https://doi.org/10.2105/AJPH.2013.301361.

7. Komro KA, Tobler AL, Delisile AL, O'Mara RJ, Wagenaar AC. Beyond the clinic; improving cild health through evidemce^ $\wedge$ based community development. BMC Pediatr. 2013;13(72) https://doi.org/10.1186/1471-243113-172.

8. Ministry of Health, Labour and Welfare (MHLW). Maternal and Child Health Act (in Japanese) http://law.e-gov.go.jp/htmldata/S40/S40HO141.html Accessed 5 Aug 2017.

9. Kuo DZ, Houtrow AJ, Arango P, Kuhthau KA, Simmons JM, Neff JM. Familycentered care: current applications and future directions in pediatric health care. Matern Child Health J. 2014(12):297-305 https://doi.org/10.1007/ s10995-011-0751-7.

10. Ministry of Health, Labour and Welfare (MHLW). Report on Regional Public Health Services and Health Promotion Services 2015 (in Japanese) http://www.mhlw.go.jp/toukei/saikin/hw/c-hoken/15/dl/kekka1.pdf. Accessed 5 Sep 2017.

11. Nakamura Y. Maternal and child health handbook in Japan. Int Med Comm 2010;53:259-65 
12. Takeuchi J, Sakagami Y, Perez R. The mother and child health handbook in Japan as a health promotion tool. Global Pediatric Health. 2016; https://doi.org/10.1177/2333794X16649884.

13. Martin KS, Wolff M, Lonczak M, Chambers M, Cooke C, Whitney G. Formative research to examine collaboration between special supplemental nutrition program for women, infants, and children and head start programs. Matern Child Health J. 2014;18:326-32.

14. Ministry of Health, Labour and Welfare (MHLW). Report on the Study Group on the ideal way to foster children's health through food and nutrition 2004; 13 (in Japanese) http://www.mhlw.go.jp/stf/seisakunitsuite/bunya/ 0000134208.html Accessed 5 Sep 2017.

15. Ministry of Health, Labour and Welfare (MHLW). Maternal and Child Health Handbook, Japan (in Japanese) http://www.mhlw.go.jp/stf/seisakunitsuite/ bunya/kodomo/kodomo_kosodate/boshi-hoken/kenkou-04.html Accessed 5 Sep 2017.

16. Ministry of Health, Labour and Welfare (MHLW). Report on National nutrition survey on preschool children.2016 (in Japanese) http://www.mhlw. go.jp/stf/seisakunitsuite/bunya/0000134208.html. Accessed 5 Sep 2017.

17. Takahashi N, Haraikawa M, Niimi S, Eto K, Ishikawa M, Kato N, et al. Characteristics of concerns about maternal and childhood nutrition which was described by nutrition educating staff in municipal maternal and child health activities-an analysis of open-ended question on pregnant women, infants, and children. Japanese J Public Health. 2016;63:569-77.

18. Eto K, Ishikawa M, Takahashi N, Haraikawa M, Niimi S, Sasaki K, et al. Implementation status and contents of nutritional guidance for infants and young children in municipalities in Japan. J Health Welf Stat. 2017;64:27-34 (in Japanese).

19. Sasaki K, Niimi S, Yamagata Z, Sato T, Akiyama C, Ogura K, et al. A nationwide survey on the subject age of 3-year old child health checkup. J Health Welf Stat. 2016;63:8-13 (in Japanese).

20. Aquino R, Oliveira NF, Barreto ML. Impact of the family health program on infant mortality in Brazilian municipalities. Am J Public Health. 2009;99:87-93 https://doi.org/10.2105/AJPH.2007.127480.

21. Bosch SO, Duch $\mathrm{H}$. The role of cognitive stimulation at home in low-income preschoolers' nutrition. Physical activity and body mass index. BMC Pediatr. 2017;17(178) https://doi.org/10.1186/s12887-017-0918-5.

22. Olson BH, Horodynski M, Herb HB, Iwanski KC. Health professionals' perspectives on the infant feeding practices of low income mothers. Maternal Child Health Journal. 2010;14:75-85.

23. Martin MA, Rothschild SK, Lynch E, Christoffel K, Pagan MM, Rodriguez JL, et al. Addressing asthma and obesity in children with community health workers: proof-of-concept intervention development. BMC Pediatr. 2016;16(198) https://doi.org/10.1186/s12887-016-0745-0.

24. Sogabe R, Maruyama R, Nakamura F, Tsuchiya R, Inoue M, Goseki M: Development of oral function and eating habits of infants living in a city area of Japan; In relation to results of dental health examinations of infants aged 14 months at public health centers. Japanese Journal of Public Health. 2010, 57: 641-648. doi: https://doi.org/10.11236/jph.57.8_641

25. Okubo H, Miyake Y, Sasaki S, Tanaka K, Hirota Y. Early sugar-sweetened beverage consumption frequency is associated with poor quality of later food and nutrient intake patterns among Japanese young children: the Osaka Maternal and Child Health Study. Nutr Res. 2016;36:594-602 https://doi.org/10.1016/..nutres.2016.01.008.

26. Ueno Y. Saeki K, Yoshimura S: the relationship between tooth eruption and ingestion of 15 food items among children aged 18-20 months. Japanese J Public Health. 2017;64:143-9 https://doi.org/10.11236/jph.64.3_143.

27. Horii N, Habi O, Dangana A, Maina A, Aizouma S, Charbit Y. Communitybased behavior change promoting child health care: a response to socioeconomic disparity. J Health, Promot Nutri. 2016;35:12 https://doi.org/10, 1186/s41043-016-0048-y.

Ready to submit your research? Choose BMC and benefit from:

- fast, convenient online submission

- thorough peer review by experienced researchers in your field

- rapid publication on acceptance

- support for research data, including large and complex data types

- gold Open Access which fosters wider collaboration and increased citations

- maximum visibility for your research: over $100 \mathrm{M}$ website views per year

At $\mathrm{BMC}$, research is always in progress.

Learn more biomedcentral.com/submissions 